\section{OPEN ACCESS}

Approved by:

Frontiers Editorial Office

Frontiers Media SA, Switzerland

${ }^{*}$ Correspondence:

Qiyong Lou

louqiyong@ihb.ac.cn

Zhan Yin

zyin@ihb.ac.cn

Specialty section: This article was submitted to Experimental Endocrinology,

a section of the journal

Frontiers in Endocrinology

Received: 19 April 2019 Accepted: 07 May 2019

Published: 22 May 2019

Citation:

Gao Y, Dai Z, Shi C, Zhai G, Jin X, He J, Lou Q and Yin Z (2019) Corrigendum: Depletion of Myostatin b Promotes Somatic Growth and Lipid Metabolism in Zebrafish.

Front. Endocrinol. 10:332. doi: 10.3389/fendo.2019.00332

\title{
Corrigendum: Depletion of Myostatin b Promotes Somatic Growth and Lipid Metabolism in Zebrafish
}

\section{Yanping Gao ${ }^{1,2}$, Ziru Dai ${ }^{1,3}$, Chuang Shi ${ }^{1,2}$, Gang Zhai ${ }^{1}$, Xia Jin ${ }^{1}$, Jiangyan $\mathrm{He}^{1}$, Qiyong Lou ${ }^{1 *}$ and Zhan Yin ${ }^{1 *}$}

${ }^{1}$ Key Laboratory of Aquatic Biodiversity and Conservation, Institute of Hydrobiology, Chinese Academy of Sciences, Wuhan, China, ${ }^{2}$ University of Chinese Academy of Sciences, Beijing, China, ${ }^{3}$ Key Laboratory of Development and High-Value Utilization of Beibu Gulf Seafood Resource, Guangxi Key Laboratory of Beibu Gulf Marine Biodiversity Conservation, College of Food Engineering, Qinzhou University, Qinzhou, China

Keywords: zebrafish, myostatin, myogenesis, lipogenesis, energy metabolism

\section{A Corrigendum on}

Depletion of Myostatin b Promotes Somatic Growth and Lipid Metabolism in Zebrafish by Gao, Y., Dai, Z., Shi, C., Zhai, G., Jin, X., He, J., et al. (2016). Front. Endocrinol. 7:88. doi: 10.3389/fendo.2016.00088

In the published article, there was an error in affiliation 2. Instead of "University of Chinese Academy of Science, Beijing, China," it should be "University of Chinese Academy of Sciences, Beijing, China."

The authors apologize for this error and state that this does not change the scientific conclusions of the article in any way. The original article has been updated.

Copyright (๑) 2019 Gao, Dai, Shi, Zhai, Jin, He, Lou and Yin. This is an open-access article distributed under the terms of the Creative Commons Attribution License (CC BY). The use, distribution or reproduction in other forums is permitted, provided the original author(s) and the copyright owner(s) are credited and that the original publication in this journal is cited, in accordance with accepted academic practice. No use, distribution or reproduction is permitted which does not comply with these terms. 